This PDF is a selection from an out-of-print volume from the National Bureau of Economic Research

Volume Title: Human Capital: A Theoretical and Empirical Analysis with Special Reference to Education (3rd Edition)

Volume Author/Editor: Gary S. Becker

Volume Publisher: The University of Chicago Press

Volume ISBN: 0-226-04119-0

Volume URL: http://www.nber.org/books/beck94-1

Conference Date: $\mathrm{n} / \mathrm{a}$

Publication Date: January 1994

Chapter Title: The Division of Labor, Coordination Costs, and Knowledge

Chapter Author: Gary S. Becker, Kevin M. Murphy

Chapter URL: http://www.nber.org/chapters/c11238

Chapter pages in book: (p. 299 - 322) 


\title{
The Division of Labor, Coordination Costs, and Knowledge 1
}

\author{
Gary S. Becker and Kevin M. Murphy
}

\section{Introduction}

Adam Smith begins his study of the wealth of nations [1965] with three chapters on the causes and consequences of the division of labor among workers. His very first sentence claims that, "The greatest improvement in the productive powers of labor, and the greater part of the skill, dexterity, and judgment with which it is anywhere directed or applied, seem to have been the effects of the division of labor." A little later he adds that, "It is the great multiplication of the productions of all the different arts, in consequence of the division of labor, which occasions, in a wellgoverned society, that universal opulence which extends itself to the lowest ranks of the people" [page 11].

We believe that the priority Smith gives to the division of labor among

\footnotetext{
'We had valuable conments from Ronald Findlay, Sergio Rebello, Andrei Shleifer, Robert Tamura, Robert Vishny, two referees, and from participants in seminars at the University of Chicago, Duke University, the University of Iowa, Queens University, Pennsylvania State University, the Stockholm School of Economics, and the Conference on Human Capital and Economic Growth, Institute for the Study of Free Enterprise Systems, University of Buffalo, May 26 and 27, 1989. Support from the Lynde and Harry Bradley Foundation, NICHD grant \#I Rol HD22054, and NSF grant \#SES85-20258 is gratefully acknowledged. David Meltzer and Rebecca Kilburn provided very useful research assistance.
} 
workers is an enormous insight. But we differ with his claim, followed by many later economists, that the degree of specialization is limited mainly by the extent of the market. Specialization and the division of labor are also influenced by several other factors that often are far more significant than the extent of the market.

A variable of great importance is the cost of combining specialized workers. Modern work on principal-agent conflicts, free-riding, and the difficulties of communication implies that the cost of coordinating a group of complementary specialized workers grows as the number of specialists increases.

The productivity of specialists at particular tasks depends on how much knowledge they have. The dependence of specialization on the knowledge available ties the division of labor to economic progress since progress depends on the growth in human capital and technologies.

The contribution of this paper is to show how specialization and the division of labor depend on coordination costs, and also on the amount and extent of knowledge. We explore implications of these relations for economic progress, industrial organization, and the activities of workers.

Section 2 develops a simple model of specialization among complementary tasks that links the division of labor to coordination costs, knowledge, and the extent of the market. Sections 3, 4, and 5 then separately consider in greater detail coordination costs, human capital, and market size. Section 6 models economic growth through endogenous increases over time in both human capital and the division of labor.

Section 7 shifts the focus from the division of labor among tasks needed to produce one good to that between workers who contribute to current consumption, and teachers who engage in roundabout production by raising the human capital of others. In an efficient allocation, teachers have more human capital than workers, and teachers who contribute to the production of consumer goods in the more distant future have greater human capital than teachers engaged in less roundabout production.

A recent paper by Yang and Borland [1991] also relates the division of labor to "transactions" costs and learning through specialization. However, since they do not consider how general knowledge affects the division of labor, they have a very different interpretation of the relation between specialization and economic progress.

\section{Division of Labor Among Tasks}

We follow Smith in recognizing that a very large number of tasks and processes are combined to produce even the most commonplace goods, 
such as pins or nails. All workers perform many tasks that conld be refined into numerous distinct subtasks. For example, labor economics is a specialized field, but some economists concentrate on labor supply, others only consider the labor supply of married women, and others are narrower still, as they analyze the labor supply of young black mothers on welfare. Even finer labor specialties wonld emerge under appropriate conditions and incentives.

To model the unlimited divisibility of tasks, we assume that a continuum of tasks along a unit interval must be performed to produce the only good $(Y)$ in the economy. "Must be performed" is modeled by the Leontief production function,

$$
Y=\min _{0 \leq s \leq 1} Y(s)
$$

although much weaker assımptions about the complementarity among tasks wonld yield similar results abont the division of labor. The rate of production from the sth task $(Y(s))$ equals the product of the working time devoted to $s\left(T_{w}(s)\right)$ and the productivity of each hour $(E(s))$ :

$$
Y(s)=E(s) T_{i v}(s) .
$$

A worker who does not specialize and performs all the tasks himself allocates his working time and investments in specific human capital among tasks to maximize the common oltput on each one. However, it is possible for workers to do better by specializing in subsets of the tasks, and then combining their ontputs with that of other workers who specialize in other tasks. The increasing returns from concentrating on a narrower set of tasks raises the productivity of a specialist above that of a jack-of-all-trades. For example, a doctor who specializes in surgery is more productive than one who performs an occasional operation because surgical skills are honed by operating, and becalıse the specialist has greater incentive to invest in surgical knowledge.

We call a "team" a group of workers who cooperate to produce $Y$ by performing different tasks and fiunctions. They can be either part of the same firm, or they can engage in transactions across different firms. "Cooperation" and "team" should not be taken to signify that team members have the same goals and do not have conflicting interests, for conflicts among members are an important consideration in our analysis.

Instead of assuming that workers have intrinsic comparative advantages at different tasks (as in the Roy model [1951]), we follow Murphy [1986], Becker [1991, Chapter 2], and Smith too [1965] in assuming that all workers are intrinsically identical. Specialization is what pro- 
duces most comparative advantages; they do not arise at birth or in childhood. Although intrinsic differences are not negligible, we have no doubt-nor did Smith-that produced differences among workers are far more important.

Since the distribution of $s$ does not have a natural metric, it is innocuous for our purposes to assume that all tasks are equally difficult and have the same degree of interdependence with other tasks. Therefore, each of the intrinsically identical members of an efficient team concentrates on an equal set of tasks, $w=1 / n$, where $n$ is the team size. Output on each task depends on the size of the set and also on the general knowledge $(H)$ available:

$$
Y=Y(H, w), Y_{h}>0, Y_{w}<0
$$

Increasing returns to specialization is captured by the assumption that $Y_{w}<0$, for otherwise there is no gain from specialization.

To illustrate the process with a specific example, assume that

$$
E(s)=d H^{\gamma} T_{h}^{p}(s),
$$

where $\theta>0$ determines the marginal productivity of $T_{h}$, the time devoted to acquiring task-specific skills. General knowledge $(H)$ is assumed to raise the productivity of the time spent investing in skills $(\gamma>0)$. The total time devoted to the sth skill is $T(s)$, so

$$
T_{h}(s)+T_{w}(s)=T(s) .
$$

Time is allocated between "investing" $\left(T_{h}\right)$ and "working" $\left(T_{w}\right)$ to maximize output, which implies that

$$
Y(s)=A(\theta) H^{\gamma} T(s)^{1+\theta},
$$

where $A=d \theta^{\theta}(1+\theta)^{-(1+\theta)}$.

If each person allocates one unit of working time uniformly among a set $w=1 / n$ of tasks, then $T(s) w=T(s)(1 / n)=1$. Substitution into equation (6) then gives output on each task as a function of team size:

$$
Y=A H^{\gamma} n^{1+\theta} .
$$

Output per team member equals

$$
y=Y / n=B(H, n)=A H^{\gamma} n^{\theta} .
$$


Clearly, $B$ rises with the size of the team as long as $\theta>0$; that is, as long as investments in task-specific skills have a positive marginal productivity.

This example can be generalized to include learning-by-doing and other considerations. But it would still retain the implication that per capita output grows with team size, so that the gains from specialization are limited only by the extent of the market. If $N$ people in a market could work with each other, equation (8) implies that output per person is maximized when $n=N$ : when everyone in the market becomes part of the same team. Since each member specializes in tasks of width $w=$ $\mathrm{I} / \mathrm{N}$, the division of labor is then limited only by $N$, market size.

Sometimes the division of labor is limited by the extent of the market, but more frequently in the modern world it is limited by other forces. Our analysis will place the extent of the market in proper perspective by considering it along with other forces that affect the degree of specialization.

Conflict among members generally grows with the size of a team because members have greater incentives to shirk when they get a smaller share of output (see, e.g., Holmstrom [ I982]). Moreover, efforts to extract rents by "holding-up" other members also grows as the number of members performing complementary tasks increases (see Chari and Jones [1991]). Further, the chances of a breakdown in production due to poor coordination of the tasks and functions performed by different members, or to communication of misleading information among members, also tends to expand as the number of separate specialists grows. In addition, coordination costs depend on whether workers trust each other, whether contracts are enforced, and whether governments maintain stable and effective laws.

Principal-agent conflicts, hold-up problems, and breakdowns in supply and communication all tend to grow as the degree of specialization increases. We call these problems part of the cost of "coordinating" specialists, and assume that the total coordination cost per member $(C)$ depends on $n$ (or $w$ ):

$$
C=C(n), \quad C_{n}>0 .
$$

Net output per team member $(y)$ is the difference between benefits and costs:

$$
y=B-C=B(H, n)-C(n), \quad B_{n}>0, C_{n}>0 .
$$

If $B$ were independent of $n$, autarchy or one-member "teams" are efficient as long as $C$ rises with $n$. If $C$ were independent of $n$, the division 
of labor is limited only by $N$, the extent of the market, as long as $B$ rises with $n$. With both $B_{n}>0$ and $C_{n}>0$, an efficient team generally has more than one member and less than all workers in the market. The efficient amount of specialization is obtained by differentiating equation (10) with respect to $n$ to get the first-order condition:

$$
B_{n} \geq C_{n}
$$

where $B_{n n}-C_{n n}<0$ is the second-order condition, and we assume that $B_{n}>C_{n}$ for small $n$. If $B_{n}>C_{n}$ for all $n \leq N$, the division of labor would be limited only by the extent of the market; otherwise, the optimal $n^{*}$ $<N$ is found where $B_{n}=C_{n}$. The efficient division of labor is then limited by coordination costs, not by market size.

The rest of the paper assumes that actual teams are efficient and maximize income per member. We believe that this is a good approximation in competitive product and labor markets, although competition may not be sufficient to achieve efficient teams when members are in different firms. Still, contractual arrangements and buyouts can offset locational and other "externalities" across firms, and would limit the discrepancies between actual and efficient teams.

\section{Coordination Costs}

A few examples might help clarify the relation between specialization and coordination costs. Most pediatricians in a city, or even in a single HMO, do not specialize in particular child hood diseases. No doubt they would learn more about a disease through specialization, but the additional knowledge would require greater expenses in coordinating their care with that of other pediatricians. For parents often do not know what is wrong with their children, and would need to see several pediatricians to get adequate care if each were highly specialized. Yet we would expect to find, and do observe, more specialization in childhood diseases that require extensive knowledge to detect and treat, such as liver diseases and cancer.

If each historian specialized in the events of only a few years, they would become more expert on developments during these shorter time periods. But since events over a few years are not isolated from those in prior and subsequent years, each one would then have to coordinate his research with that of several other specialists. Such coordination costs can be greatly reduced by specialization in larger and more selfcontained periods. 
Economists and lawyers working on the relation between law and economics can coordinate their research, but coordination costs are reduced when economists also become lawyers or lawyers also become economists, as with the increasing number of persons who take advanced degrees in both law and economics. Yet it is not surprising that joint degrees are more common in law and economics than in health economics, since the investment required for a medical degree is much greater than for a law degree.

The family in most traditional societies has an extensive division of labor between husbands, wives, children, and sometimes other kin. Extensive specialization was made easier by the altruism and caring among family members. These lowered coordination costs by reducing the tendency for members to shirk and try to extract greater shares of their family's production (see the discussion in Becker [1991, Chapter 2]).

A rather enormous literature has studied the comprehensive division of labor found in insect colonies. Although genetically based, the degree of specialization does respond to changes in the environment. For example, the division of labor by age among honeybees is less extensive in smaller colonies-a measure of the extent of the market. The division of labor among bees also responds to the spatial organization of colonies, the demands of brood rearing, difficulties of communicating food sources, and other determinants that often can reasonably be considered to be "coordination" costs (see Winston [1987, pp. 101-7]).

An analysis of the cost of coordinating specialized tasks and functions provides insights into many aspects of the organization of firms and industries. Specialized members of a team who are employed by the same firm get coordinated by the rules of the firm, whereas specialists who are employed by different firms have their activities coordinated by contracts and other agreements that govern transactions across firms. Companies that cut the material for a dress manufacturer or supply car doors to General Motors are part of the "teams" producing particular dresses or General Motors cars. In market economies of the modern era, even firms involved in producing the simplest goods, such as pencils, use many downstream and upstream firms to produce these goods, so that modern teams are very large.

Companies are less "vertically" integrated when it is cheaper to coordinate specialized team members through market transactions. This is why companies are more specialized when they can economize on transactions costs by locating near each other-as the computer industry locates in Silicon Valley, the United States clothing industry was once concentrated on the West Side of Manhattan, and much of the small arms industry during the mid-nineteenth century squeezed into a small area of Birmingham (see Allen [1929]). 
An important function of entrepreneurs is to coordinate different types of labor and capital: economists like John Bates Clark [1899] believed that this is their main function. Economic systems that encourage entrepreneurship would have lower costs of coordination, and presumably a more widespread division of labor among workers and firms. Since centrally planned economies throttle entrepreneurship as well as weaken the capacity of markets to coordinate transactions, workers and firms should be less specialized in these economies than in market economies. Unfortunately, there is no systematic evidence on the degree of specialization among workers in the formerly Communist economies of Eastern Europe, although there is abundant evidence that firms were large and carried vertical integration to ridiculous extremes, or so it appears in comparisons with market economies.

In a stimulating article many years ago, Hayek [1945] stressed the importance to an economy of coordinating efficiently the specialized knowledge of different participants: ". . . the problem of a rational economic order is ... the utilization of knowledge which is not given to anyone in its totality," and "Through [the price system] not only a division of labor but also a coordinated utilization of resources based on an equally divided knowledge has become possible." Hayek's insight is that the cost of coordinating specialized workers is smaller, and hence the division of labor is greater, in economies that make effective use of prices and markets to coordinate tasks and skills across firms.

Hayek did not emphasize an even more significant implication of his analysis, although he must have been aware of it. The specialized knowledge at the command of workers is not simply given, for the knowledge acquired depends on incentives. Centrally planned and other economies that do not make effective use of markets and prices raise coordination costs, and thereby reduce incentives for investments in specialized knowledge.

\section{Knowledge and Specialization}

The division of labor and specialization both within and between countries increased enormously during the past several centuries as much of the world became vastly richer. Sixteenth century European cities had perhaps a few hundred occupations, whereas a telephone directory for even a small American city now lists thousands of specialized services. Probably no more than 15 percent of physicians in the nineteenth century were specialists-neither general practitioners nor pediatricianswhile in recent years over 75 percent of United States physicians special- 
ize. ${ }^{2}$ The first three economic journals started in the United States were general purpose journals - the Quarterly Journal of Economics in 1886, the Journal of Political Economy in 1892, and the American Economic Review in 1911-whereas most of the many journals established in recent years are highly specialized: the Journal of Applied Econometrics, the Journal of Legal Studies, and the Journal of Economic Demography are a few examples.

Engineers of the early nineteenth century were not highly specialized. But the growth of industries based on new technologies and greater knowledge of science during the nineteenth and twentieth centuries led to many engineering specialties. The British Institute of Civil Engineering started in 1818; the mechanical engineers started their own society in 1847; the electrical engineers in 1871; the automobile engineers in 1906; and so on until chemical and other specialized societies emerged during the past 70 years (see Buchanan [1989]).

The engineering, medical, and economics examples illustrate that much of the growth in specialization over time has been due to an extraordinary growth in knowledge. We assume as in equation (8) that an increase in the knowledge embodied in the human capital of workers not only raises the average product per team member, but also raises the marginal product of a larger team:

$$
\frac{\partial}{\partial H}\left(\frac{\partial B}{\partial n}\right)=B_{n h}>0
$$

The presumption built into equation (4) is that general knowledge is usually complementary with investments in task-specific knowledge.

By differentiating the first-order condition (11) that maximizes income per worker with respect to $H$, one gets

$$
\frac{d n^{*}}{d H}=\frac{B_{n h}}{C_{n n}-B_{n n}}>0,
$$

where $B_{n}-C_{n n}<0$ is the second-order condition. The inequality in (12) signs these derivatives, and it is necessary if our model is to explain why economic development and the growth in knowledge raise specialization and the division of labor.

Equation (13) indicates that teams get larger and workers become

\footnotetext{
"See Peterson and Pennell [1962] and Shapiro [1989]. Note, however, that U.S. physicians are inuch more specialized than those in Canada and Western Europe (see Fuchs and Hahn [1990]).
} 
more specialized and expert over a smaller range of skills as human capital and technological knowledge grow. Adam Smith recognizes the relation between specialization and knowledge when he states that the division of labor ". . . is generally carried further in those countries which enjoy the highest degree of industry and improvement ..." [ I965, p. 5]. However, in his discussion the causation went from the division of labor to greater knowledge, while in ours it also goes from greater general knowledge to a more extensive division of labor and greater taskspecific knowledge.

The "jack-of-all-trades" is less useful than the specialist in economies with advanced technologies and an extensive human capital base. Although workers in modern economies have considerable knowledge of principles and have access to complicated technologies, a typical worker also commands a very much smaller share of the total knowledge used by the economy than do workers in simpler and more backward economies.

It is the extensive cooperation among highly specialized workers that enables advanced economies to utilize a vast amount of knowledge. This is why Hayek's emphasis on the role of prices and markets in combining efficiently the specialized knowledge of different workers is so important in appreciating the performance of rich and complex economies.

An "expert" has been facetiously defined as "someone who knows more and more about less and less." Highly specialized workers are surely experts in what they do, and yet know very little about the many other skills found in a complex economy. Modern expertise comes partly at the expense of narrowness, and of ignorance about what other people do.

Equation (12) also helps determine how workers with different knowledge get allocated to different sectors. The costs involved in "coordinating” specialists surely differ greatly among sectors; for example, costs are relatively low in dense urban communities, and in industries where suppliers and downstream firms locate near each other and communicate easily. The effects of higher coordination costs on specialization and the division of labor are exacerbated by the optimal allocation of workers among sectors.

An efficient allocation "assigns" workers whose productivity is least affected by coordination costs to the high cost sectors. This implies that workers with lower human capital would be assigned to the high cost sectors if greater coordination costs lower the marginal product of human capital (see Becker [1991, Appendix]). The first-order condition for $n$ and the envelope theorem show that this is the case since 


$$
\frac{\partial^{2} y}{\partial H \partial \lambda}=\frac{\partial\left(B_{h}\right)}{\partial \lambda}=B_{h n} \frac{\partial n^{*}}{\partial \lambda}<0,
$$

where $\lambda$ is a coordination-cost-raising parameter, with $c_{n \lambda}>0, B_{n n}>0$ by equation (13), and $\partial n^{*} / \partial \lambda$ is clearly $<0$. This analysis explains, among other things, why earnings are usually higher in large cities even after adjusting for observable measures of human capital-such as years of schooling and experience (see, e.g., Fuchs [1967]) - because unobserved human capital is also attracted to cities by the lower coordination costs.

\section{Extent of the Market}

Adam Smith recognized that specialization had costs as well as benefits since it made workers "stupid" and "ignorant." ${ }^{\text {"3 }}$ But Smith forcefully stated his belief that the division of labor is limited mainly by the extent of the market. The modern literature on specialization within a profession [Baumgardner, 1988], increasing returns and specialization in international trade [Krugman, 1987], the degree of brand proliferation [Lancaster, 1975], and on the economic gains from population growth (e.g., Simon [1977] and Locay [1990]) has followed this emphasis on the limitations to the division of labor imposed by the extent of the market.

In our formulation also, the division of labor is limited by market size when $n^{*}$, the optimal number of team members, is greater than or equal to $\mathrm{N}$, the number of workers in the market. In that case, each worker specializes in different skills, so that each has some monopoly power ex post (see Gros [1987] and Baumgardner [1988]). This may well describe the position of many specialists in small towns and rural areas.

However, every reasonably large metropolitan area has several, often many, persons who have essentially the same specialized skills and compete in the same market. Pediatricians in the same HMO or psychiatrists

\footnotetext{
3 "The man whose life is spent performing a few simple operations has no occasion to exert his understanding or to exercise his invention ... and generally becomes as stupid and ignorant as it is possible for a human creature to become" [Smith, 1965, p. 734].

Due to this and similar statements, some scholars have seen a serious contradiction in Smith's approach to the division of labor: Book I extols its advantages, while Book IV points out its corrupting influence (e.g., see the discussion in Marx [1961] and West [1964], but see Rosenberg [1965]). But surely there is no necessary contradiction between Smith's recognition that the division of labor entails major costs, and his belief that the division of labor is crucial in promoting the wealth of nations. The contradiction is with Smith's belief that the division of labor is limited mainly by the extent of the market.
} 
who work out of a psychoanalytic institute have closely related skills and seek patients in the same geographic market. Any publisher in a major city has access to many copy editors and translators with very similar skills.

The division of labor cannot be limited mainly by the extent of the market when many specialists provide essentially the same skills. Our claim is that instead it is usually limited by the costs of coordinating workers with different specialties, as in the examples discussed in Section 3 .

We recognize that it is possible to reinterpret our examples by emphasizing quality differences among specialists who only appear to have the same skills, or by claiming they are in separate local markets. By the same token, however, the illustrations provided by Smith and others to support the emphasis on the extent of the market can often be reinterpreted in terms of coordination costs. For example, the division of labor may be greater in cities than in small towns not because markets are larger in cities, but because it is easier to coordinate specialists in more densely populated areas.

There even seems to be a problem with Smith's justly famous example of a pin factory, where workers specialize in various functions, including drawing out, straightening, and cutting the wire. Why didn't the several factories that made pins in Smith's England combine their activities, get a larger scale and market, and specialize more within each factory? If the answer is that the cost of combining these factories exceeded the gain from a greater division of labor, then specialization was limited by these costs of "coordination," not by the extent of the market." Again, the answer may be that the pins were of very different qualities, or that each factory catered to a separate local market, although pins were cheap to ship and Smith does not mention the quality of pins.

Perhaps the most significant difference between our approach and that based on market size lies in the divergent interpretations of the enormous growth in specialization as countries develop. We claim that the huge increase in scientific and other knowledge and decline in coordination costs raised the benefits from greater specialization. The alter-

\footnotetext{
4Stigler's important elaboration of the connection between the division of labor and the extent of the market [ 1951$]$ recognizes that the Smithian view appears to lead to specialized producers and monopolistic suppliers. He asks, ". . . why does the firm not abandon the functions subject to increasing returns, allowing another firm (and industry) to specialize in them to take full advantage of increasing returns?" [p. 188]. His answer that "these functions may be too small to support a specialized firm or firms" [p. 188] is inadequate because a firm need not specialize only in these functions. Each firm could be the sole provider of some functions subject to increasing returns and one of several providers of functions subject to decreasing returns.
} 
native view suggested by Smith's approach is that declines in transportation costs raised the effective size of markets. Surely both sets of forces were operating, although the expansion in knowledge and decline in coordination costs seem by far to be the more fundamental forces. Indeed, some of the growth in markets was not even exogenous, but rather the search for larger markets was induced by the increase in knowledge and decline in coordination costs that raised the gain from larger teams with more specialized members.

\section{The Growth in Specialization and Knowledge}

However, the growth in knowledge also is not exogenous, for it depends on investments in new technologies, basic research, and human capital. The incentive to invest in knowledge depends partly on the degree of specialization and the level of task-specific skills. In other words, there is not a one-way correlation between knowledge and the division of labor, but mutual determination.

To show in a simple way the interaction between the division of labor, the accumulation of knowledge, and economic growth, we consider the functional form given by equation (8) after netting out a constant elasticity coordination cost function:

$$
y_{t}=A_{t} H_{t}^{\gamma} n_{t}^{\theta}-\lambda_{t} n_{t}^{\beta} .
$$

The first-order condition for optimal $n$ implies that

$$
n_{i}^{*}=\left(\frac{\theta}{\beta \lambda_{i}}\right)^{1 /(\beta-\theta)} A_{i}^{1 / \beta-\theta} H_{t}^{\gamma /(\beta-\theta)},
$$

where $\beta>\theta>0$ is the second-order condition. Replacing $n$ in equation (15) by the right-hand side of equation (16) gives optimal output as a function of general knowledge and various parameters:

$$
y_{t}^{*}=k_{t} A_{t}^{\beta /(\beta-\theta)} H_{t}^{\gamma \beta /(\beta-\theta)},
$$

with

$$
k_{t}=\lambda_{t}^{-\theta /(\beta-\theta)}\left[\left(\frac{\theta}{\beta}\right)^{\theta /(\beta-\theta)}-\left(\frac{\theta}{\beta}\right)^{\beta /(\beta-\theta)}\right]>0
$$

Equation (17) divides the change in per capita income into the growth in human capital $(H)$, the growth in technology $(A)$, and the decline in coordination costs $(\lambda)$ : 


$$
\frac{d \log y}{d t}=\frac{\gamma \beta}{\beta-\theta} \frac{d \log H}{d t}+\frac{\beta}{\beta-\theta} \frac{d \log A}{d t}-\frac{\theta}{\beta-\theta} \frac{d \log \lambda}{d t} .
$$

There is not a separate entry for coordination costs in the usual growth accounting calculus, so $-(\theta / \beta-\theta)(d \log \lambda / d t)$ would be considered part of the "residual" along with the effects of the growth in $A$, and some of the effects of changes in $H$.

To endogenize the accumulation of human capital, we consider a simple one-sector model where the human capital of period $t+1$ is just the unconsumed output of period $t$ (the next section considers a separate human capital sector):

$$
H_{t+1}=y_{t}-c_{t}=A_{t} H_{t}^{\gamma} n_{t}^{\theta}-\lambda_{t} n_{t}^{\beta}-c_{t},
$$

where $c_{t}$ is consumption in $t$.

If $\gamma<1$, diminishing returns to the accumulation of knowledge discourage further investment as this stock of knowledge grows. Admittedly, knowledge is not subject to diminishing returns in the same obvious way as is physical capital because greater knowledge raises the productivity of further investment in knowledge. However, as knowledge continues to grow, limited human capacities tend to make it harder to pack more knowledge into a person without running into diminishing returns. This is why $\gamma<1$ seems to be a plausible assumption.

Autonomous technological progress in the neoclassical model offsets the diminishing returns to a higher capital-labor ratio. In our model the induced expansion in the division of labor as human capital grows raises the marginal product of additional knowledge. Equation (17) shows that the total elasticity of output with respect to human capital exceeds $\gamma$ since $\beta>\beta-\theta$. The reason is that an increase in $H$ has an indirect effect on $y$ through the induced increase in $n$. This indirect effect is stronger the larger $\theta$ is relative to $\beta$ : the bigger is $n$ 's effect on the productivity of specialized production compared with its effect on coordination costs. As it were, greater specialization enables workers to absorb knowledge more easily, which offsets to some extent the tendency toward diminishing returns from the accumulation of knowledge.

The model is completed with a conventional separable utility function defined over consumption into the indefinite future:

$$
U=\frac{1}{\sigma} \sum_{t=0}^{\infty} \alpha^{t} c_{t}^{\sigma}, \quad \text { with } \sigma<1 .
$$

Present consumption is transformed into future consumption through the production of human capital. If the rate of return on investment 
in human capital is denoted by $r$, the first-order conditions for optimal consumption over time are

$$
\alpha\left(c_{t+1}, c_{t}\right)^{1-\sigma}=R_{t}=1+r_{t}, \quad t=0,1, \ldots
$$

With the given inherited knowledge stock, $H_{0}$, the first-order conditions in equations (16) and (22), and the production function in equation (15) determine the optimal path over time of $c, H$, and $y$. These variables converge to constant values at a steady state if the rate of return continues to fall without limit as capital grows, they converge to a steadystate growth path if the rate of return becomes independent of the capital stock, and they grow at increasing rates if the rate of return rises as capital grows.

Since a higher $H_{t+1}$ means equally lower $c_{t}$ (given $y_{t}$ ), the transformation between $c_{t-1}$ and $c_{t}$ gives the rate of return on changes in $H_{t}$. By the envelope theorem this equals the derivative of $y^{*}$ in equation (17) with respect to $H$ :

$$
R_{t}=-\frac{d y_{t+1}}{d c_{t}}=\frac{d y_{t+1}}{d H_{t+1}}=\frac{\beta \gamma}{\beta-\theta} k_{t} A_{t}^{\beta /(\beta-\theta)} H_{t}^{[\beta \gamma /(\beta-\theta)]-1},
$$

where $k$ is defined in equation (20).

The rate of return falls, is constant, or rises with higher $H$, as $\beta \gamma \geqq \beta-\theta$. If $\beta \gamma=\beta-\theta$, and $A$ and $\lambda$ are constant over time, steadystate growth in $y, H$, and $c$ starts from any initial $H_{0}$ at a rate equal to

$$
1+g=\frac{c_{t+1}}{c_{t}}=\frac{y_{t+1}}{y_{t}}=\frac{H_{t+1}}{H_{t}}=\left(R \alpha^{-1}\right)^{1 / 1-\sigma}
$$

If $\beta \gamma<\beta-\theta$, and $A$ is constant, the economy converges to a stationary state $(g=0)$. If $\beta \gamma>\beta-\theta$, and $A$ is constant, rates of growth in $Y, H$, and $c$ all increase over time. In Yang and Borland's model [1991] the growth rate must eventually decline because gains from a greater division of labor are eventually exhausted.

Equations (16) and (24) show that output per capita, knowledge, and the division of labor all grow together over time. Growth in these variables is interdependent, as causation runs from knowledge to the division of labor and output, as well as from the division of labor to knowledge and output. The equilibrium rate of growth at all moments is Pareto optimal since there are no externalities in the model.

Rates of growth in output and human capital are higher when the level of technology $(A)$ is greater. These growth rates may be quite re- 
sponsive to better technology because the induced expansion in specialization raises the exponent of $A$ to $\beta / \beta-\theta>1$.

Equations (18) and (23) show that rates of return on investments in knowledge depend on the cost of coordinating specialized workers $(\lambda)$. Countries with lower coordination costs due to stabler and more efficient laws, or other reasons, not only have larger outputs, but they also tend to grow faster because lower costs stimulate investments in knowledge by raising the advantages of a more extensive division of labor.

\section{The Division of Labor Between Sectors: Teachers and Workers}

Workers specialize in the production of different goods as well as in different tasks required to produce a single good. For example, an experienced steel worker who has accumulated considerable skill at firing blast furnaces would be much less productive in the computer software industry. The discussion in previous sections of the advantages from specialization at tasks implies that workers become specialized to particular sectors partly because they become skilled at the tasks specific to a sector.

In discussing specialization across sectors, we continue to assume that all workers are identical to start, but they become different by investing in different skills at particular tasks. Each good is produced by teams that perform a very large number of specialized complementary tasks, where the productivity of each team depends on parameters of the relevant production function and the human capital of team members.

To analyze specialization across sectors, we consider the production function in each sector that has optimized out the endogenous team size. Output depends explicitly only on the human capital of team members, but implicitly it also depends on coordination costs and other parameters that determine specialization and the division of labor. The marginal products of human capital partly depend on the benefit and cost parameters that determine the optimal division of labor in each sector. Differences across sectors in these marginal products lead to sectoral differences in the human capital per worker. There is abundant evidence that years of schooling per worker differ greatly among industries (see Gill [1989] and Mincer and Higuchi [1988]).

Given our emphasis on the relation between the division of labor, the accumulation of knowledge, and economic progress, the discussion of specialization across sectors concentrates on differences between the consumption and investment sectors. We drop the assumption of Section 6 that human capital is simply unspent consumer goods, and introduce more realistic assumptions about the way human capital is produced. 
To simplify the presentation, we consider only a special case of the production function for consumer goods in equation (17): $\beta \gamma=\beta-\theta$, and $A$ and $k$ are both normalized to unity. Therefore,

$$
C_{t}=N_{r i} H_{r i}
$$

The term $H_{c t}$ refers to the human capital of each person in the consumption sector in period $t, N_{c t}$ is the number of these persons-we call this the number of "workers" in period $t$-and $C_{t}$ is the aggregate output of consumer goods.

All persons who help produce human capital are called "teachers." We assume that human capital lasts for only one period, and that teachers in period $t$ produce the human capital of both workers and teachers in period, or "cohort," $t+1$. All persons in each cohort spend their "youthful" time as students acquiring the human capital that prepares them to become workers or teachers when they become adults. The human capital acquired by a student depends on the human capital of her teachers, and the number of teachers per student.

The human capital acquired by students is assumed to be proportional to the human capital of teachers $\left(H_{T}\right)$, where the factor of proportionality depends on the number of teachers per student $(\tau)$ :

$$
H_{t+1}=F\left(\tau_{\ell}\right) H_{\tau}, F^{\prime}>0, F^{\prime \prime}<0,
$$

where we shall show that $\varepsilon$, the elasticity of $F$ with respect to $\tau$, must fall as $\tau$ increases. Since this is a reduced form, $H_{T}$ is the human capital of each teacher in a human capital production "team," and $\tau$ is the number of students per member of each team.

The assumption $F^{\prime}>0$ means that an increase in "class size"-a decrease in $\tau$-reduces the human capital acquired by each student. This relation may not hold for all values of $\tau$, but obviously it pays to economize on teachers when fewer teachers do not lower the human capital produced per student. Although many empirical studies do not find that larger classes reduce the learning of students (see the review in Hanushek [1989]), a good recent study by Card and Krueger [1990] finds that workers earn more if they went to schools with smaller classes. Moreover, an experiment conducted by Tennessee that randomly assigned students to classes of different sizes also found that smaller classes improved performance (see Finn and Achilles [1990]).

It is somewhat surprising that the concavity of $F$ and the assumption that output in both the consumption and human capital sectors are proportional to the human capital of persons employed in each sector do not imply that students who prepare for different sectors acquire the 
same amount of human capital. Instead, the production functions in equations (25) and (26) imply a finely calibrated inequality between the human capital of workers and teachers in efficient allocations of persons and investments.

The teachers of workers in period $j$ were students in period $j-1$, their teachers were students in $j-2$, and so on, continuing backwards until one comes to the persons in the initial period who indirectly taught the workers in $j$. In essence, $C_{j}$ is not simply produced by the workers in that period and their teachers, but also by the whole sequence over time of teachers who helped train these workers.

We define the $j$ th "lineage" as this sequence of teachers and students in successive periods that ends in period $j$ because the students in $j$ become workers then. A lineage is a "team" of teachers, students, and workers in different periods who combine to produce consumer goods. The human capital of workers in later periods is produced with more "roundabout" methods, and hence has longer lineages, than the human capital of workers in earlier periods.

The roundabout methods used to produce human capital can be seen by substituting repeatedly into equation (26) to express the human capital of persons in period $t$ who belong to the $j$ th lineage as

$$
H_{j t}=H_{j 0} F\left(\frac{N_{j 0}}{N_{j l}}\right) \cdots F\left(\frac{N_{j t-1}}{N_{j t}}\right), j=0, \ldots, t \leq j,
$$

where $N_{t^{\prime}}$ is the number of teachers in lineage $j$ in period $t^{\prime}(<t)$, and $H_{j 0}$ is the human capital of the $N_{j 0}$ initial teachers in this lineage. By substituting equation (27) into (25), we get

$$
C_{j}=H_{j j} N_{j j}=H_{j 0} F\left(\frac{N_{j 0}}{N_{j 1}}\right) \cdots F\left(\frac{N_{i j-1}}{N_{j j}}\right) N_{j j} .
$$

We only consider accumulations of human capital that are efficient, that maximize consumption in any period, given consumptions in all other periods. It is obvious that the teacher-student ratios within a lineage then cannot be constant over time because marginal products in the lineage would be zero for all members. The negative effect on the production of human capital from having an additional student in a lineage would exactly cancel the positive effect of subsequently having an additional teacher. The Appendix shows that efficient teacher-student ratios would fall over time within each lineage, so that teaching in a lineage would become less intensive as the lineage becomes closer to training workers who produce consumer goods. 
Another important implication is due both to the concavity of the human capital production function with respect to the teacher-student ratio and the constant returns to scale in the consumption sector with respect to the number of workers. As a result of these assumptions, it is efficient to provide students who are further removed from becoming workers with more extensive training, so that teacher-student ratios would be higher in the more roundabout lineages (see the Appendix). Consequently, the human capital of members of more roundabout lineages grows over time relative to those of less roundabout ones.

Even though the economy only has one consumption good and homogeneous human capital, the efficient accumulation of human capital creates an infinite number of sectors or lineages. Members of a particular sector would be specialized to that one partly because their human capital would be too little for the more roundabout sectors and too much for the less roundabout ones.

In addition, workers and teachers specialize in particular tasks within their sectors. Since more roundabout lineages have greater human capital, the analysis in Section 2 of the effects of human capital on the degree of specialization implies that members of the more roundabout sectors tend to specialize in a narrower range of tasks.

The distribution of human capital evolves over time. The human capital within each lineage grows at decreasing rates, but the slower-growing lineages are culled out over time when their members produce consumer goods, and the faster-growing lineages expand in size. Since lower-order lineages disappear over time, all human capital in later periods is "descended" from the teachers of persons in a small number of highly roundabout lineages in the initial period.

Inequality in the distribution of human capital at any moment expands over time because the human capital of sectors with greater human capital (the higher-order lineages) grows faster. However, the inequality would fall over time because the sectors with the least human capital (the lower-order lineages) are culled out and eliminated. We have not been able to reach any general conclusions about the net effect of these opposing forces on charges over time in the distribution of human capital.

What is rather remarkable about these rich implications concerning teacher-student ratios and the growth of human capital in different lineages is that they apply to any efficient path over time. Several additional properties hold if the economy is in a steady-state equilibrium, with consumption and human capital in each lineage growing at the same constant rate. For example, the inequality in this distribution of human capital across lineages tends to be greater when the steady-state growth rate 
is higher. However, we do not want to emphasize steady-siate properties, for it is not clear that a steady state exists, given the restrictions on the teacher-student function implied by an efficient equilibrium.

\section{Summary}

This paper considers specialization and division of labor both within and between sectors. Workers concentrate on different tasks and combine their activities in "teams" to produce each sector's output. A more extensive division of labor raises productivity because returns to the time spent on tasks are usually greater to workers who concentrate on a narrower range of skills.

The traditional discussion of the division of labor inaugurated by Adam Smith emphasizes the limitations to specialization imposed by the extent of the market. Limited markets sometimes curtail the division of labor, but we claim that the degree of specialization is more often determined by other considerations. Especially emphasized are various costs of "coordinating" specialized workers who perform complementary tasks, and the amount of general knowledge available.

On this view, specialization increases until the higher productivity from a greater division of labor is just balanced by the greater costs of coordinating a larger number of more specialized workers. Consequently, principal-agent conflicts, hold-up problems, communication difficulties, and other costs of combining specialized workers into productive teams play a major part in our approach. Since teams may include workers in different firms, costs of coordination also depend on the efficiency of markets and how well contracts are enforced.

Greater knowledge tends to raise the benefits from specialization, and thus tends to raise the optimal division of labor. This helps explain why workers become more expert on narrower ranges of tasks as knowledge grows and countries progress. Increased specialization in turn raises the benefits from investments in knowledge, so that the growth in tandem of specialization and investments in knowledge may allow an economy to continue to develop.

The paper also considers the division of labor between workers who produce consumer goods and teachers who produce human capital. The analysis distinguishes among teachers of workers in the initial period, teachers of the teachers of workers in the following period, and so on for teachers engaged in more and more roundabout production of workers. We show than an efficient economy has a finely etched division of labor, where teachers have more human capital than workers, and 
teachers in higher-order lineages - in more roundabout productionhave greater human capital than teachers in lower-order ranges.

Adam Smith's emphasis on the importance of specialization and the division of labor to economic progress is not simply an influential landmark in the development of economics. An analysis of the forces determining the division of labor provides crucial insights not only into the growth of nations, but also into the organization of product and labor markets, industries, and firms.

\section{Appendix}

Equation (28) implies that the marginal products of workers in any lineage are

$$
\begin{gathered}
\frac{d C_{j}}{d N_{j k}}=\frac{C_{j}}{N_{j k}}\left\{\varepsilon\left(\frac{N_{j k}}{N_{j k+1}}\right)-\varepsilon\left(\frac{N_{j k-1}}{N_{j k}}\right)\right\}, k<j \\
\frac{d C_{i}}{d N_{j j}}=\frac{C_{j}}{N_{i j}}\left\{1-\varepsilon\left(\frac{N_{j j-1}}{N_{j j}}\right)\right\}, k=j>0,
\end{gathered}
$$

where $\varepsilon(\tau)=F(\tau) \times \tau / F(\tau)$, is the elasticity of the human capital production function with respect to the teacher-student ratio. Marginal products in the final period of a lineage are positive only if this elasticity is less than one in the period before the end of the lineage. Moreover, equation (29) shows that marginal products will not be positive in periods prior to the end unless in each lineage the elasticities with respect to the teacher-student ratio are increasing over time.

ln addition, the marginal products in equation (29) would rise with a reduction in the number of members in a lineage only if the elasticity of human capital with respect to the teacher-student ratio falls as the ratio increases. Then a reduced number of members in the $k$ th period raises the elasticity when they are teachers (since the teacher-student ratio falls) and lowers the elasticity when they are students (since the teacher-student ratio rises). Both effects imply that marginal products are positive only when the teacher-student ratio is falling over time within each lineage.

These results also have strong implications for differences across lineages. An optimal allocation of the labor force between lineages requires that the marginal rates of substitution between persons in any periods $i$ 
and $k$ be the same for members of all lineages (say $j$ and $m$ ). By equations (29) and (30) this implies that

$$
\left(\frac{N_{j i}}{N_{j k}}\right) \frac{\varepsilon_{j k}-\varepsilon_{j k-1}}{\varepsilon_{j i}-\varepsilon_{j i-1}}=\frac{N_{m i}}{N_{m k}} \frac{\varepsilon_{m k}-\varepsilon_{m k-1}}{\varepsilon_{m i}-\varepsilon_{m i-1}}
$$

where $\varepsilon_{j k}$ is $\varepsilon\left(N_{j l} / N_{j l+1}\right)$, and $\varepsilon_{j j}=1$ for all $j$ and $k$. When $i=j=1, k=0$, and $m=2$, equation (31) becomes

$$
\left(\frac{N_{11}}{N_{10}}\right) \frac{\varepsilon_{10}}{1-\varepsilon_{10}}=\left(\frac{N_{21}}{N_{20}}\right) \frac{\varepsilon_{20}}{\varepsilon_{21}-\varepsilon_{20}} .
$$

Since $\varepsilon_{21}$ must be less than one for the marginal product of workers in this lineage to be positive in period two, then $\varepsilon_{20}<\varepsilon_{10}$ to satisfy equation (32). Given that elasticities decline with the teacher-student ratio, this ratio must be higher in period 0 for the second than for the first lineage.

Similar conditions hold over longer horizons. Not only must the teacher-student ratio decline over time within a lineage, but it also increases as a line age becomes more round about. This implies that human capital grows faster over time in more round about lineages.

\section{References}

Allen, George C. The Industrial Development of Birmingham and the Black Country, 1860-1927 (London: George Allen \& Unwin Ltd., 1929).

Baumgardner, James R. "The Division of Labor, Local Markets, and Worker Organization." Journal of Political Economy XCVI (June 1988), 509-27.

Becker, Gary S. A Treatise on the Family, enlarged edition (Cambridge, MA: Harvard University Press, 1991).

Buchanan, R. A. The Engineers: A History of the Engineering Profession in Britain, 1750-1914 (London: Jessica Kingsley Publishers, 1989).

Card, David, and Alan B. Krueger. "Does School Quality Matter? Returns to Education and the Characteristics of Public Schools in the United States." NBER Working Paper, May, 1990.

Chari, V. V., and Larry E. Jones. "A Reconsideration of the Problem of Social Cost: Free Riders and Monopolists." Federal Reserve Bank of Minnesota, June, 1991.

Clark, John B. The Distribution of Wealth: A Theory of Wages, Interest and Profts (New York: Macmillan, 1899).

Finn, Jeremy D., and Charles M. Achilles. "Answers and Questions About Class Size: A Statewide Experiment." American Educational Research Journal XXVII (Fall 1990), 557-77.

Fuchs, Victor R. "Differentials in Hourly Earnings by Region and City Size, 
1959." Occasional paper \#I0I (New York: NBER), I967. An excerpt was published in Monthly Labor Review XC (January 1967), 22-26.

Fuchs, Victor R., and James H. Hahn. "How Does Canada Do It? A Comparison of Expenditures for Physicians' Services in the United States and Canada." New England Journal of Medicine CCCXXIII (September 27, 1990), 884-90.

Gill, Indermit. "Technological Change, Education and Obsolescence of Human Capital: Some Evidence for the U.S." Ph.D. thesis, University of Chicago, 1989.

Gros, Daniel. "Protectionism in a Framework with Intra-industry Trade: Tariffs, Quotas, Retaliation, and Welfare Losses." International Monetary Fund Staff Papers XXXIV (March 1987), 439-76.

Hanushek, Eric A. "The Impact of Differential Expenditures on School Performance." Educational Researcher XVIII (May 1989), 45-5 I, 62.

Hayek, F. A., "The Use of Knowledge in Society." American Economic Review XXXV (September 1945), 519-30.

Holmstrom, Bengt. "Moral Hazard in Teams." Bell Journal of Economics XIII (Fall I982), 324-40.

Krugman, Paul R. "The Narrow Moving Band, the Dutch Disease, and the Consequences of Mrs. Thatcher: Notes on Trade in the Presence of Dynamic Scale Economics." Journal of Development Economics XXVII (1987), 4I-55.

Lancaster, Kelvin. "Socially Optimal Product Differentiation." American Economic Review LXV (September 1975), 580-85.

Locay, Luis. "Economic Development and the Division of Production Between Households and Markets." Journal of Political Economy XCVII (October I990), 965-82.

Marx, Karl. Capital (Moscow: Foreign Languages Publishing House, I96I).

Mincer, Jacob, and Yoshio Higuchi. "Wage Structures and Labor Turnover in the United States and Japan." Journal of the Japanese and International Economics II (1988), 97-II3.

Murphy, Kevin M. "Specialization and Human Capital." Ph.D. thesis, University of Chicago, 1986.

Peterson, P. Q., and M. Y. Pennell. Health Manpower Source Book, Section I4: Medical Specialists (Washington, DC: United States Public Health Service, 1962).

Rosenberg, Nathan. "Adam Smith on the Division of Labour: Two Views or One?" Economica XXXII (May I965), I27-39.

Roy, Andrew D. "Some Thoughts on the Distribution of Earnings." Oxford Economic Papers N.S. III (June I95I), I35-46.

Shapiro, David B., Reference Data on Physician Manpower (Chicago: American Medical Association, 1989).

Simon, Julian. The Economics of Population Growth (Princeton, NJ: Princeton University Press, 1977).

Smith, Adam. The Wealth of Nations (New York: Modern Library, 1965).

Stigler, George J. "The Division of Labor is Limited by the Extent of the Market." Journal of Political Economy LIX (June I95I), I85-93.

West, E. G., "Adam Smith's Two Views on the Division of Labour." Economica XXXI (February 1964), 23-32. 
Winston, Mark K, The Biology of the Honeybee (Cambridge MA: Harvard University Press, 1987).

Yang, Xiaokai, and Jeff Borland. "A Microeconomic Mechanism for Economic Growth." Journal of Political Economy XCIX (June 1991), 460-82. 